Article

\title{
Formation of Phases and Porous System in the Product of Hydrothermal Treatment of $\chi-\mathrm{Al}_{2} \mathrm{O}_{3}$
}

\author{
Svetlana R. Egorova ${ }^{1, *}$, Aliya N. Mukhamed'yarova ${ }^{1}$, Oksana V. Nesterova ${ }^{1}$, Yuqing Zhang ${ }^{1,2}$, \\ Juliya D. Skibina ${ }^{1}$ and Alexander A. Lamberov ${ }^{1}$ \\ 1 Alexander Butlerov Institute of Chemistry, Kazan Federal University, Kazan 420008, Russia; \\ anm03@list.ru (A.N.M.); oksana-nesterova@bk.ru (O.V.N.); coolkidsun@live.cn (Y.Z.); \\ ulia08_96@mail.ru (J.D.S.); lamberov@list.ru (A.A.L.) \\ 2 Institute of Chemistry, Chemical Engineering and Materials, Heilongjiang University, Harbin 150080, China \\ * Correspondence: segorova07@gmail.com; Tel.: +7-917-898-7803
}

Received: 7 November 2017; Accepted: 9 January 2018; Published: 11 January 2018

\begin{abstract}
The presence of $\chi-\mathrm{Al}_{2} \mathrm{O}_{3}$ resulting from thermal decomposition gibbsite as part of alumina catalysts is unfavorable because of its acid characteristics. One of the available techniques of $\chi-\mathrm{Al}_{2} \mathrm{O}_{3}$ removal is crystallization under hydrothermal conditions into boehmite, which is a main precursor of active $\gamma-\mathrm{Al}_{2} \mathrm{O}_{3}$. The influence of products of the hydrothermal treatment of $\chi-\mathrm{Al}_{2} \mathrm{O}_{3}$ obtaining in result of thermal decomposition gibbsite under $T=150-200{ }^{\circ} \mathrm{C}, P=0.5-1.5 \mathrm{MPa}$ and $\mathrm{pH}=4.0-9.2$ were studied. The hydrothermal treatment products in these conditions are gibbsite and boehmite phases which are formed coincidently by parallel ways. In the alkaline medium at $\mathrm{pH}=8.0-9.2$ three-dimensional parallelepiped boehmite crystals with the edge length $>200 \mathrm{~nm}$ are formed, at $\mathrm{pH}=4.0$ two-dimensional rhombic-shaped plates with thickness $20-100 \mathrm{~nm}$ and with the edge length $\sim 80-500 \mathrm{~nm}$ are formed. Crystallization of coarse boehmite particles promotes the formation of large and closed mesoporous.
\end{abstract}

Keywords: alumina; boehmite; gibbsite; hydrothermal treatment

\section{Introduction}

Active alumina $\left(\gamma-\mathrm{Al}_{2} \mathrm{O}_{3}\right)$ is widely used in the chemical industry as catalysts for petrochemical and refinery processes, catalyst supports and adsorbents [1-5]. $\chi-\mathrm{Al}_{2} \mathrm{O}_{3}$ is one of the most acidic modifications of alumina. $\chi-\mathrm{Al}_{2} \mathrm{O}_{3}$ has the concentration of the Lewis acid sites 1.8-4.0 times more than $\gamma-\mathrm{Al}_{2} \mathrm{O}_{3}$ [6]. Therefore, the $\chi-\mathrm{Al}_{2} \mathrm{O}_{3}$ presence as part of alumina catalysts and catalyst supports structure in various petrochemical and oil refining catalytic processes is unfavorable. The strong Lewis acid sites of $\chi-\mathrm{Al}_{2} \mathrm{O}_{3}$ usually catalyze the side effect of cracking, coking and hydrocarbons oligomerization reactions [7], which decrease the selectivity of the process of the main products.

$\chi-\mathrm{Al}_{2} \mathrm{O}_{3}$ is formed during the thermal decomposition of the dispersed particles of gibbsite during obtaining $\gamma$-alumina. $x-\mathrm{Al}_{2} \mathrm{O}_{3}$ is obtained as $\mathrm{X}$-ray amorphous products of mechanochemical or thermochemical activation of gibbsite [8]. The alumina is a part (up to $\sim 38 \mathrm{wt} \%$ [9]) of the products of the thermal decomposition of course gibbsite floccules. One of the available techniques of $\chi-\mathrm{Al}_{2} \mathrm{O}_{3}$ removal from alumina support is its crystallization under hydrothermal conditions into boehmite, which is a main precursor of active $\gamma$-alumina.

Currently, the phase transition of $\chi-\mathrm{Al}_{2} \mathrm{O}_{3}$ in hydrothermal conditions has been studied poorly, because this process is described in a small amount of research works $[10,11]$. Authors $[10,11]$ establish that boehmite and gibbsite were formed in the products of hydrothermal treatment (HTT) of $\chi-\mathrm{Al}_{2} \mathrm{O}_{3}$ at the $130-150{ }^{\circ} \mathrm{C}$. It was reported that gibbsite $\left(\gamma-\mathrm{Al}(\mathrm{OH})_{3}\right)$ preferably crystallizes in the low-temperature conditions at the $120-130{ }^{\circ} \mathrm{C}$ in amount of $16 \mathrm{wt} \%$. Boehmite $(\gamma-\mathrm{AlOOH})$ is formed at $150{ }^{\circ} \mathrm{C}$ in the 
amount of 70-80 wt \% (4-61 h). Thus, as showing in [10,11], the sequence of the phase transition of the $x-\mathrm{Al}_{2} \mathrm{O}_{3} \mathrm{HTT}$ (hydrothermal treatment) can be presented by the Scheme 1.

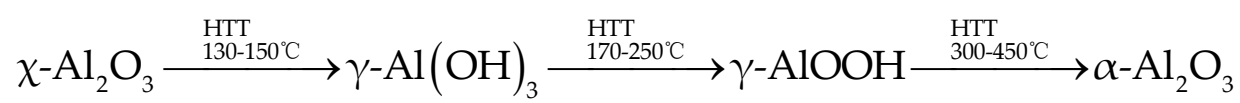

Scheme 1. The sequence of the phase transition of the $x-\mathrm{Al}_{2} \mathrm{O}_{3}$ HTT.

This scheme is debatable, and further research is needed to clarify it.

In this research, common factors of aluminum hydroxides formation of the phase transition of $\chi-\mathrm{Al}_{2} \mathrm{O}_{3}$ into hydroxides and the samples porous system, resulting in the HTT of $\chi-\mathrm{Al}_{2} \mathrm{O}_{3}$ at the temperature range of $150-200{ }^{\circ} \mathrm{C}$ in the aqueous suspension $(\mathrm{pH}=4.0-9.2)$ at the appropriate saturated vapor pressure of water were studied.

\section{Materials and Methods}

$\chi-\mathrm{Al}_{2} \mathrm{O}_{3}$ was synthesized by thermal treatment $\left(T=550^{\circ} \mathrm{C}, \tau=180 \mathrm{~min} ; \tau\right.$ : continuance of HTT $)$ of gibbsite powder of GD00 brand (JSC "SUAL", Kamensk-Uralsky, Russia), dispersed previously in the planetary micro mill (Pulverisette 7, FRITSCH, Idar-Oberstein, Germany) until the medium floccules' size of particles $6.1 \mu \mathrm{m}$.

Hydrothermal treatment (HTT) of $\chi-\mathrm{Al}_{2} \mathrm{O}_{3}$ was performed in a BuchiGlasUster Limbo li autoclave (Büchi AG, Uster, Switzerland) with automated temperature and pressure control in a $450 \mathrm{~mL}$ stainless steel reactor at an alumina mass ratio of water 1:5 under agitation with a stirrer at speed of $500 \mathrm{rpm}$ and maximum degree of autoclave filling of $70 \%$ (Figure 1). The effect of temperature on the phase composition of HTT products was investigated at the initial $\mathrm{pH}$ of the suspension $(\mathrm{pH}=9.2)$ in the range of $T=150-200{ }^{\circ} \mathrm{C}$, and the effect of the $\mathrm{pH}$ of the suspension at $T=190^{\circ} \mathrm{C}$. The aqueous medium was alkalized via passing of a part of sodium ions remained after the gibbsite dispersion from $\chi-\mathrm{Al}_{2} \mathrm{O}_{3}$ into solution. The $\mathrm{pH}$ values of $8.0,6.0$ and 4.0 were provided by addition of the acetic acid solution to the suspension. Sampling was carried out in a mode of raising the temperature to the set temperature 20 and $40 \mathrm{~min}$ after the autoclave was switched on and in isothermal mode after reaching the set temperature for 0-180 min. The prescribed temperature was carried out in approximately $60 \mathrm{~min}$. The autoclave reactor was cooled by feeding cold water into its jacket. As a result, its temperature decreased to $100{ }^{\circ} \mathrm{C}$ during $20 \mathrm{~min}$.

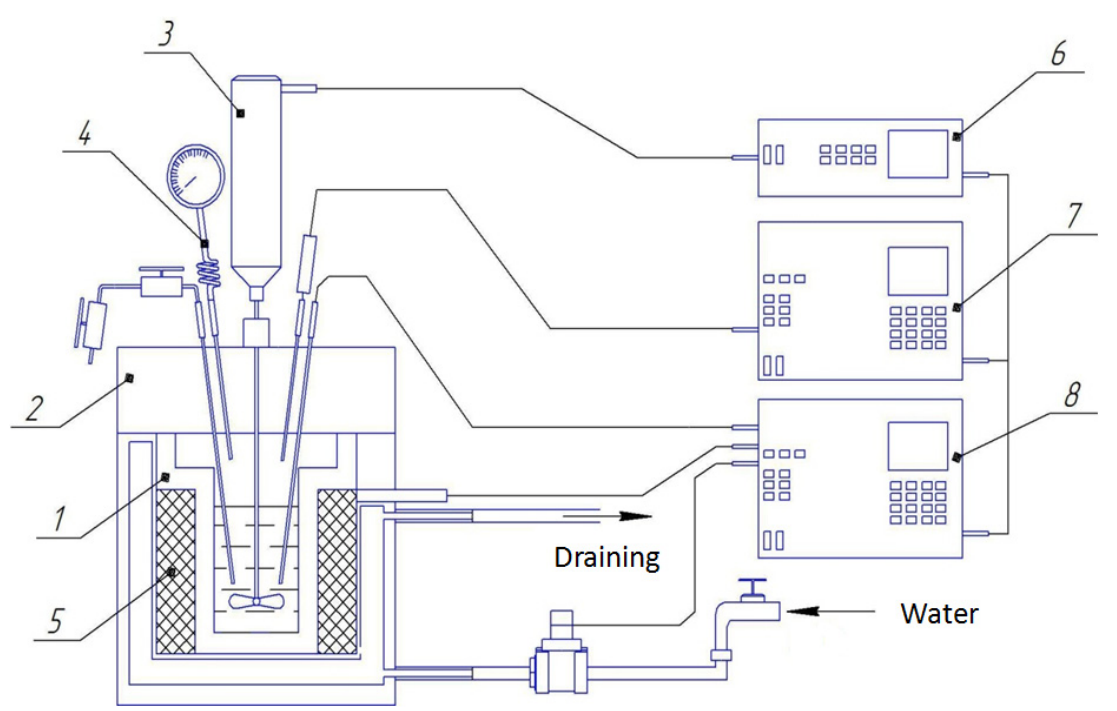

Figure 1. Diagram of the autoclave. 1: reactor; 2: reactor cover; 3: mixing device; 4: manometer; 5: electric furnace; 6: control unit for agitator; 7: pressure control unit; 8: temperature control unit. 
X-ray powder diffraction (XRPD) studies of samples were made using a MiniFlex 600 diffractometer (Rigaku, Toyko, Japan) equipped with a D/teX Ultra detector. In this experiment, $\mathrm{Cu} \mathrm{K} \alpha$ radiation $(40 \mathrm{kV}, 15 \mathrm{~mA})$ was used and data were collected at room temperature in the range of $2 \theta$ from $2^{\circ}$ to $100^{\circ}$ with a step of $0.02^{\circ}$ and exposure time at each point of $0.24 \mathrm{~s}$ without sample rotation. The coherent scattering region (CSR) sizes $D_{(h k l)}$ were calculated using the Scherrer equation:

$$
D_{(h k l)}=K \lambda /(\beta \cos \theta)
$$

which is limited by the uncertainties in $K$, the crystallite shape factor, and $\beta$, which is the pure diffraction broadening. Diffraction intensities were measured by scanning from $20^{\circ}$ to $80^{\circ}(2 \theta)$ with a step size of $0.02^{\circ}(2 \theta)$. The phase identification was done according to the presence of the following diffracted lines in X-ray spectrum: $\gamma$-Al(OH) ${ }_{3}$ (ICDD No. 01-076-3811), $\gamma$-AlOOH (ICDD No. 00-021-1307), $\gamma$ - $\mathrm{Al}_{2} \mathrm{O}_{3}$ (ICDD No. 00-010-0425), $\chi-\mathrm{Al}_{2} \mathrm{O}_{3}$ (PDF Card No. 00-013-0373).

The phase concentrations were obtained using the thermal analysis (TA; Netzsch STA-449C Jupiter analyser coupled with a QMS 403 Aeolos quadrupole mass-spectrometer, Netzsch, Selb, Germany). The TA was carried out in such a way to be capable of recording the thermogravimetric (TG), derivative thermogravimetric (DTG) and differential thermal analysis (DTA) curves simultaneously. The samples were heated in the temperature range of $30-1000{ }^{\circ} \mathrm{C}$ at the uniform heating rate of $10^{\circ} \mathrm{C} / \mathrm{min}$ in an argon flow. Concentrations of aluminum hydroxides were calculated from the amount of the water released during the aluminum hydroxides dehydration and $\chi-\mathrm{Al}_{2} \mathrm{O}_{3}$ dehydroxilation.

The specific surface area $S_{\mathrm{BET}}$ (a specific surface area calculated with the Brunauer-Emmett-Teller method) and the pore volume $V_{\mathrm{BET}}$ (a pore volume calculated with the Brunauer-Emmett-Teller method) were determined using a multipurpose Quantachrome Autosorb-iQ analyser (Quantachrome Instruments, Boynton Beach, FL, USA). The specific surface area was calculated based on the specific surface area $0.162 \mathrm{~nm}^{2}$ and density $0.808 \mathrm{~g} / \mathrm{cm}^{3}$ of a nitrogen molecule $\mathrm{N}_{2}$ in the normal liquid state. Adsorption isotherms were obtained at $-196{ }^{\circ} \mathrm{C}(77 \mathrm{~K})$ after the degassing of samples at $150{ }^{\circ} \mathrm{C}$ under the residual pressure of $0.013 \mathrm{~Pa}$. The pore volumes' distributions over the pore diameters were calculated from the curve of desorption isotherm by using the standard Barret-Joyner-Highland mechanism.

The measurements by scanning electron microscopy (SEM) were carried out with an EVO 50XVP electron microscope combined with an INCA 350 energy-dispersive spectrometer (Carl Zeiss, Upper Cohen, Germany). The spectrometer resolution was $130 \mathrm{eV}$. The analysis was carried out at acceleration voltage of $20 \mathrm{kV}$ and flange back distance of $8 \mathrm{~mm}$. The measurements by a transmission electron microscopy (TEM) were carried out with a microscope Hitachi HT7700 Excellence (Hitachi, Tokyo, Japan).

\section{Results and Discussion}

As showing in the recently investigation [12], the particles of $\chi-\mathrm{Al}_{2} \mathrm{O}_{3}$ have the bedded structure inherited from gibbsite (Figure 2a). They consist of a number of plates, between which there are extended cracks-macropores with a width of $\sim 30 \mathrm{~nm}$. The particles are composed in parallel arranged plates consisting of small particles having a spherical shape and size $\sim 9-46 \mathrm{~nm}$. The shatters of size 21-270 $\mathrm{nm}$ are arranged in a disorderly manner on the external face of plates.

The HTT products at $\mathrm{pH}$ and temperature ranges are gibbsite and boehmite identified on the diffractograms by characteristic diffracted lines (Figure 3). The gibbsite and boehmite decomposition is exhibited by two endothermic effects on the DSC (Differential Scanning Calorimetry) curves [12] and in the Table S1 in the Supplementary Materials. A feature of the formed gibbsite is the small size of its particles. The dehydration of the particles on DSC curves is not accompanied by the endothermic effect of the conversion of boehmite $\rightarrow \gamma-\mathrm{Al}_{2} \mathrm{O}_{3}$. Therefore, its content was calculated based on the amount of water released as a result of the following reaction:

$$
2 \gamma-\mathrm{Al}(\mathrm{OH})_{3} \rightarrow \chi-\mathrm{Al}_{2} \mathrm{O}_{3}+3 \mathrm{H}_{2} \mathrm{O}
$$




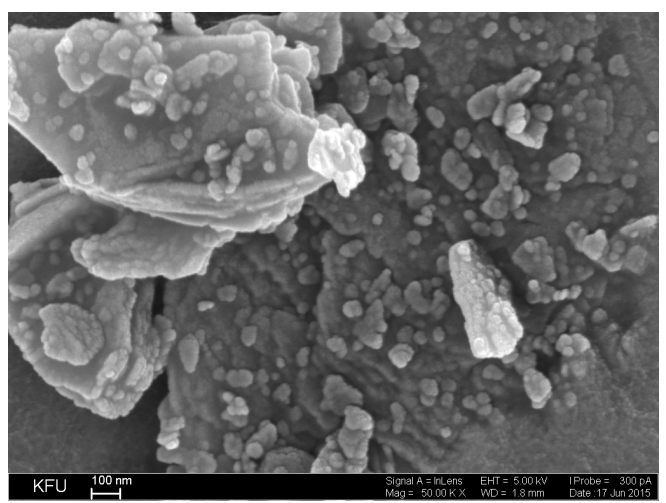

(a)

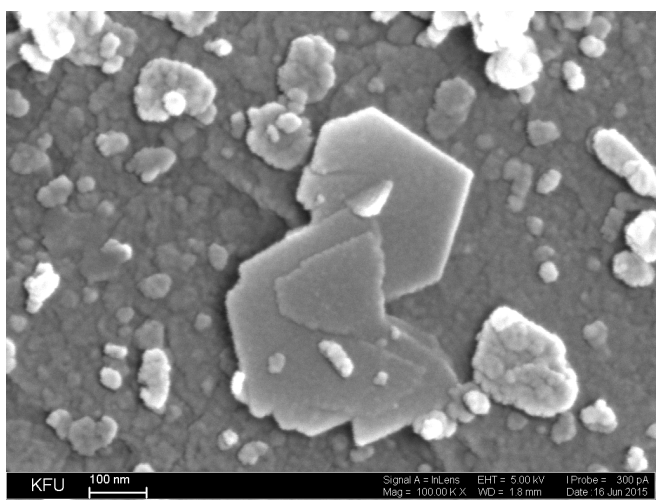

(b)

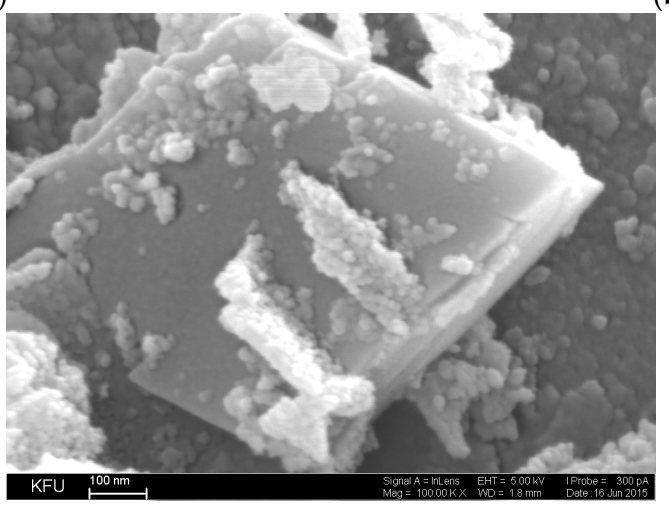

(c)

Figure 2. SEM images of external surface of (a) starting $\chi-\mathrm{Al}_{2} \mathrm{O}_{3}$ particle, its products of HTT at (b) $\mathrm{T}=190{ }^{\circ} \mathrm{C}, \mathrm{pH}=4.0, \tau=60 \mathrm{~min}$; (c) $\mathrm{T}=180^{\circ} \mathrm{C}, \mathrm{pH}=9.2, \tau=60 \mathrm{~min}$.

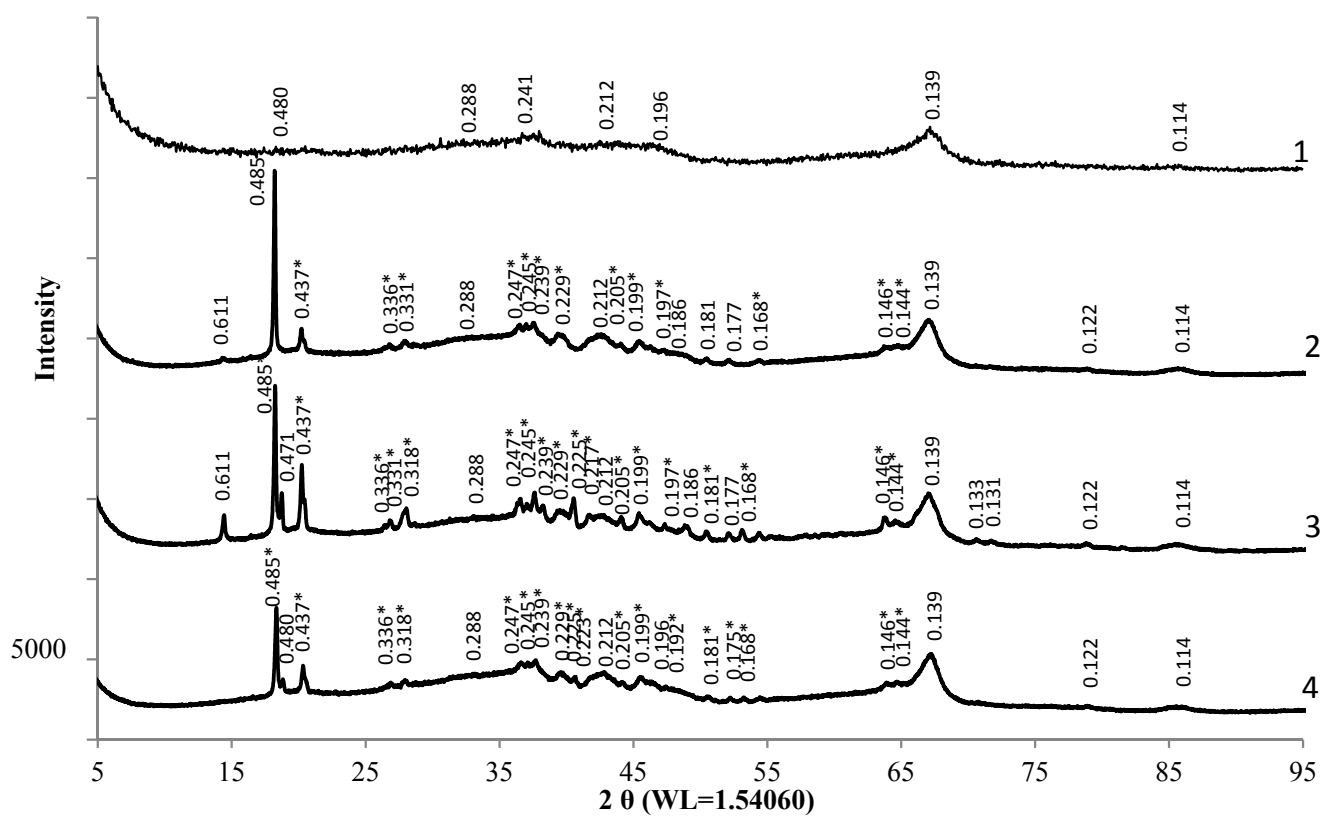

Figure 3. Diffractograms of (1) starting $\chi-\mathrm{Al}_{2} \mathrm{O}_{3}$ and its products of $\mathrm{HTT}$ at (2) $\mathrm{T}=190{ }^{\circ} \mathrm{C}, \mathrm{pH}=4.0$, $\tau=40 \mathrm{~min},(3) \mathrm{T}=180^{\circ} \mathrm{C}, \mathrm{pH}=9.2, \tau=40 \mathrm{~min}$, and (4) $\mathrm{T}=150{ }^{\circ} \mathrm{C}, \mathrm{pH}=9.2, \tau=40 \mathrm{~min}$ in the mode of temperature rise. "**": gibbsite.

$\chi-\mathrm{Al}_{2} \mathrm{O}_{3}$ crystals are thin irregularly shaped porous plates with a pore diameter of $\sim 2-5 \mathrm{~nm}$. $\chi-\mathrm{Al}_{2} \mathrm{O}_{3}$ are described of the hexagonal structure by diffraction of electrons with $d_{(214)}=0.139 \mathrm{~nm}$, 
$d_{(200)}=0.241 \mathrm{~nm}$ (Figure 4a-d) [13]. The crystals of the gibbsite formed are transparent non-porous plates of hexagonal shape with a typical electron diffraction pattern for electron diffraction with $d_{(021)}=0.245 \mathrm{~nm}, d_{(330)}=0.146 \mathrm{~nm}$ (Figure $4 \mathrm{c}$ ). The length of the edge of the hexagonal gibbsite crystals reaches $200 \mathrm{~nm}$ on the TEM images (Figure $4 \mathrm{a}, \mathrm{c}$ ), while the calculated values of the dimensions of the CSR gibbsite along the (002) and (110) planes are 40.4-48.9 nm and 29.4-40.9 nm respectively.

The most intensively gibbsite crystallizes in the regime of temperature rise (Figure $5 \mathrm{a}-\mathrm{d}$ ), which reaches $119-137{ }^{\circ} \mathrm{C}$ and $143-182{ }^{\circ} \mathrm{C}$ after 20 and $40 \mathrm{~min}$ on the furnace of the autoclave turning respectively. In accordance with the phase diagrams of $\mathrm{Al}_{2} \mathrm{O}_{3}-\mathrm{H}_{2} \mathrm{O}$, the low-temperature regime is more preferable for the formation of gibbsite. As a result, in the samples synthesized in the temperature-raising mode, the proportion of gibbsite reaches $16.8 \mathrm{wt} \%$ (Figure $5 \mathrm{a}, \mathrm{b}$ ), which agrees with the literature data $[14,15]$. At the same time, boehmite is not yet formed by the $20 \mathrm{~min}$, and by the $40 \mathrm{~min}$ at $161-182^{\circ} \mathrm{C}$ its amount increases only to $9.0-13.1 \mathrm{wt} \%$ (Figure $5 \mathrm{c}, \mathrm{d}$ ).

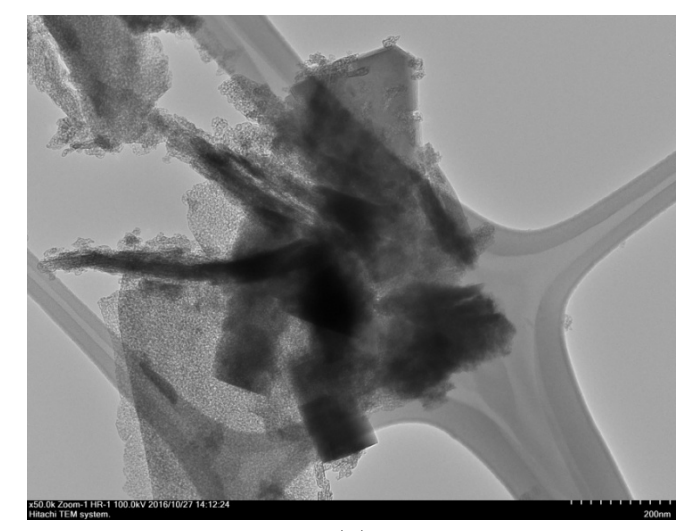

(a)
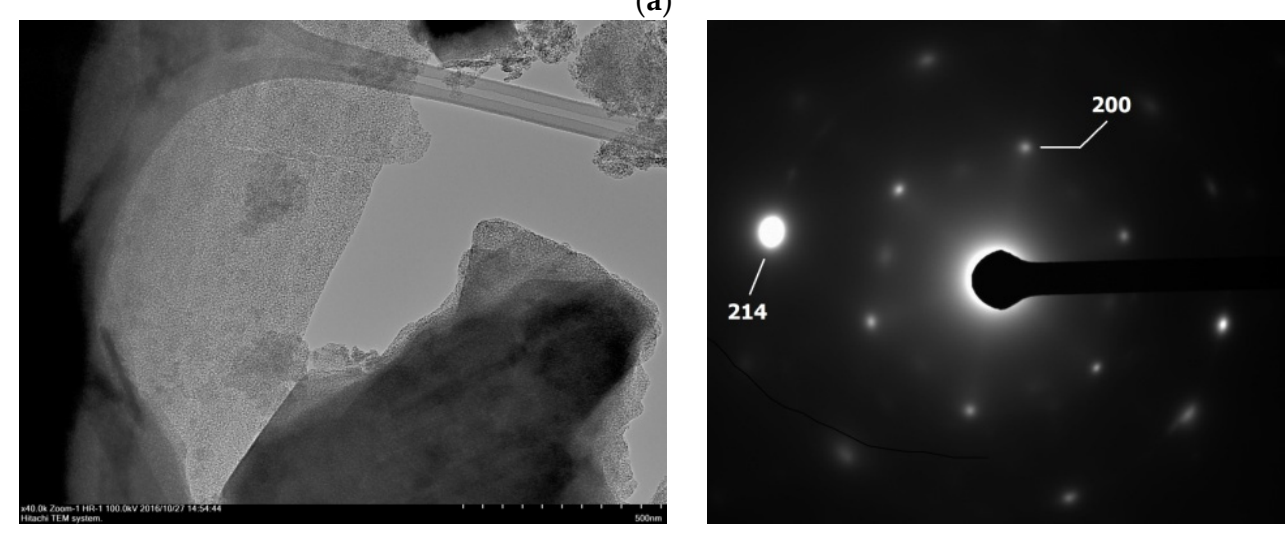

(b)
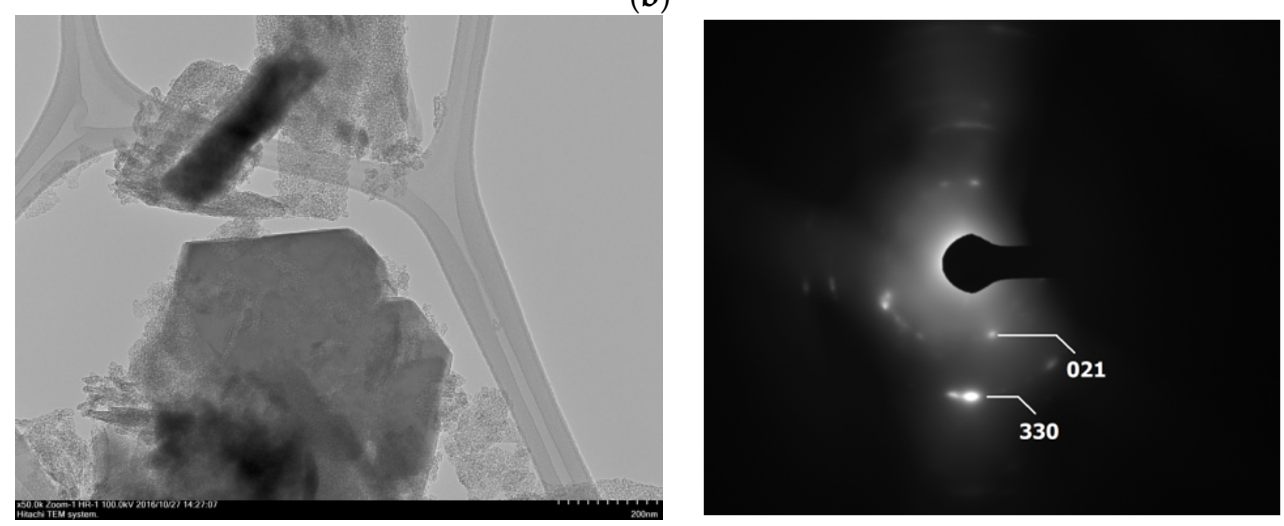

(c)

Figure 4. Cont. 

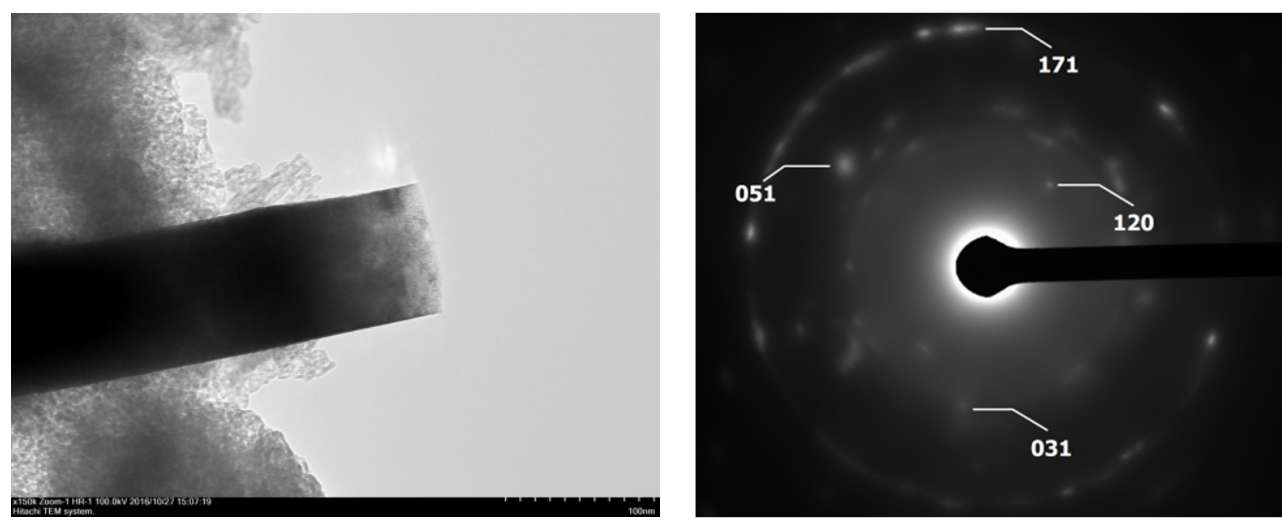

(d)

Figure 4. TEM images of (a) $\chi-\mathrm{Al}_{2} \mathrm{O}_{3} \mathrm{HTT}$ product and the selected areas of surface for the electron diffraction of the individual structure $(\mathbf{b}-\mathbf{d})$. Sample composition: (b) $\mathrm{C}\left(\chi-\mathrm{Al}_{2} \mathrm{O}_{3}\right)=63.0$ wt \%; (c) $\mathrm{C}($ boehmite $)=31.0 \mathrm{wt} \%$; (d) $\mathrm{C}($ gibbsite $)=6.0 \mathrm{wt} \%$.

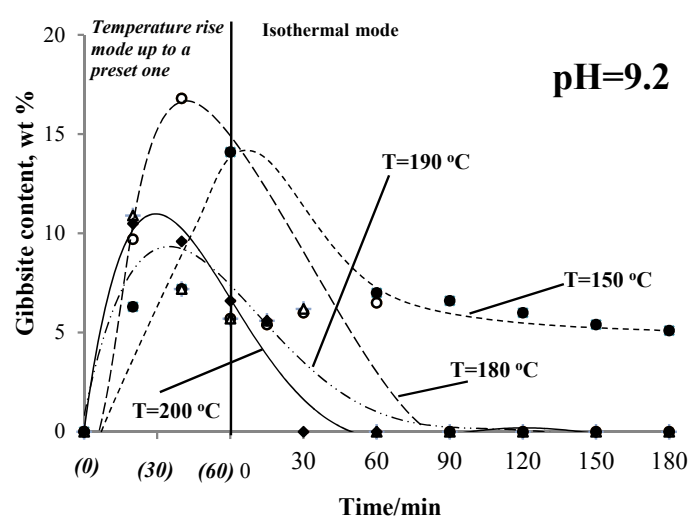

(a)

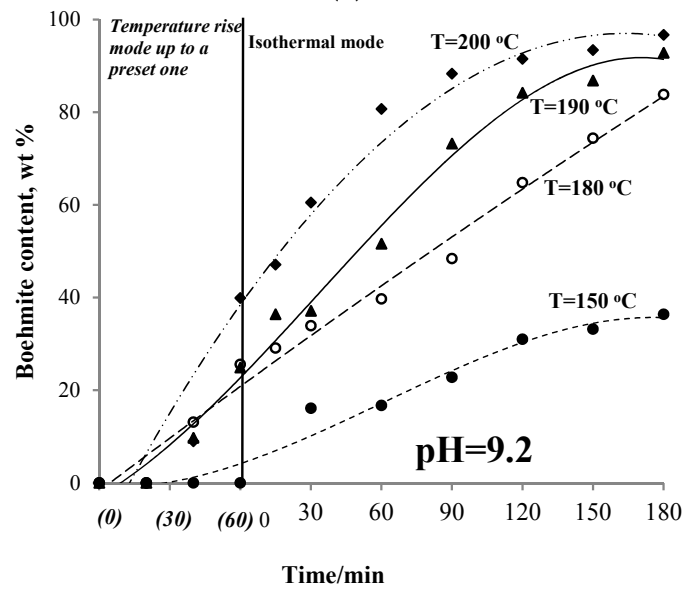

(c)

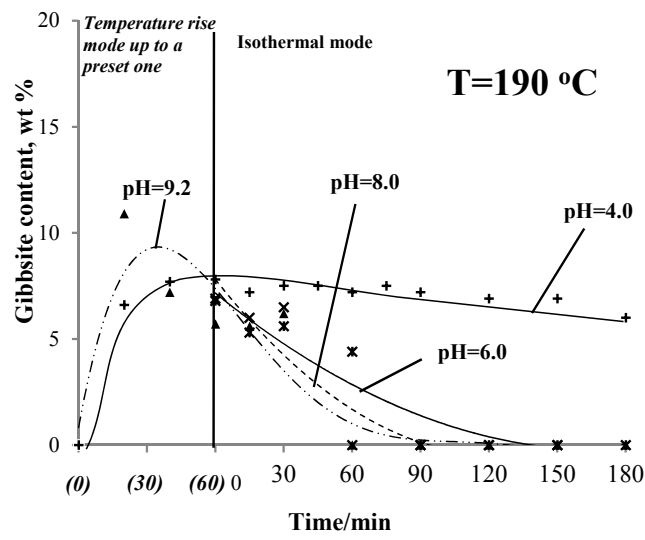

(b)

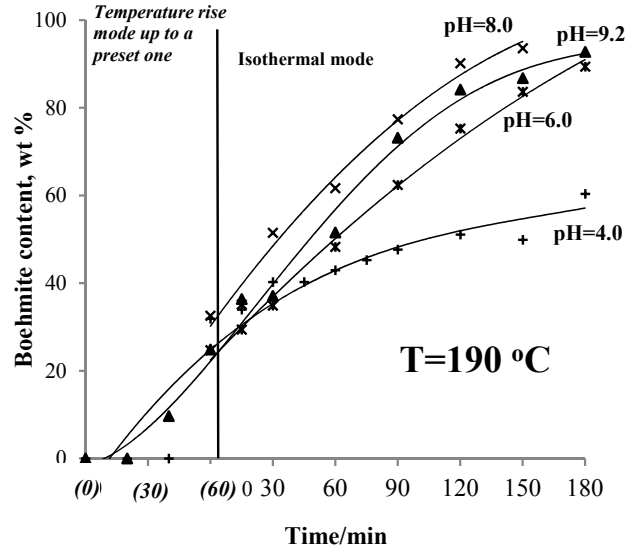

(d)

Figure 5. Dependences of an aluminum hydroxides content on the on the duration in the $\chi-\mathrm{Al}_{2} \mathrm{O}_{3} \mathrm{HTT}$ products $(\mathbf{a}, \mathbf{c})$ at the different temperatures and $(\mathbf{b}, \mathbf{d}) \mathrm{pH}$ value of an aqueous suspension.

In the isothermal mode, the gibbsite are crystallized the least. The amount of gibbsite after $180 \mathrm{~min}$ of $\mathrm{HTT}$ at $150{ }^{\circ} \mathrm{C}$ and $\mathrm{pH}=9.2$ or $\mathrm{pH}=4.0$ and $\mathrm{T}=190{ }^{\circ} \mathrm{C}$ is $5.1-6.0 \mathrm{wt} \%$. The amount of gibbsite after HTT at $190-200{ }^{\circ} \mathrm{C}$ and $\mathrm{pH}=6.0-9.2$ decreases to $0.0 \mathrm{wt} \%$ due to a reduction in the rate of formation and/or partial dehydration. The crystallization of boehmite is preferred under such 
conditions. Therefore, its amount reaches $89.4-97.1 \mathrm{wt} \%$. Such a significant increase in the proportion of boehmite in the absence of gibbsite in the products of $\chi-\mathrm{Al}_{2} \mathrm{O}_{3}$ HTT allows us to assume that both aluminum hydroxides crystallize simultaneously by parallel routes in accordance with Scheme 2.

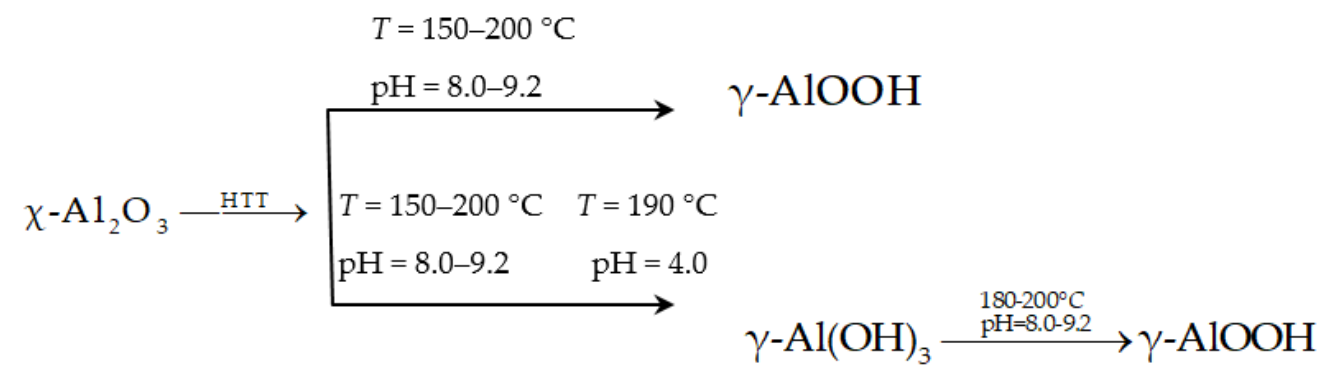

Scheme 2. The sequence of the phase transition of the $x-\mathrm{Al}_{2} \mathrm{O}_{3}$ HTT at the $T=150-200{ }^{\circ} \mathrm{C}$ and $\mathrm{pH}=4.0-9.2$.

The boehmite crystals on TEM micrographs are identified as non-porous parallelepipeds of $\sim 200 \mathrm{~nm}$ in length and $\sim 50 \mathrm{~nm}$ in width (Figure $4 \mathrm{~d}$ ) with a ring pattern of electron diffraction obtained from a site with such fragments and characteristic for boehmite rings with $d / l_{(031)}=0.234 \mathrm{~nm}$, $d / l_{(120)}=0.316 \mathrm{~nm}, d / l_{(051)}=0.186 \mathrm{~nm}, d / l_{(171)}=0.138 \mathrm{~nm}[7,16]$.

The $\mathrm{pH}$ of the suspension has a significant effect on the morphology of the boehmite crystals. As follows from the SEM images (Figure $2 \mathrm{~b}, \mathrm{c}$ ), at $\mathrm{pH}=4.0-6.0$ mainly two-dimensional, and at $\mathrm{pH}=8.0-9.2$, three-dimensional crystals of boehmite are formed. In both cases, the crystals grow by successive layers in the form of stepped terraces on the surface of the $\chi-\mathrm{Al}_{2} \mathrm{O}_{3}$ particles. It testifies about the realization of the mechanism for the boehmite and gibbsite formation through the dissolution of oxide crystals with the formation of crystallization centers and crystal-forming complexes of a new phase and their subsequent integration into the surface layer of nucleus.

The production of predominantly lamellar boehmite crystals in an acid medium is due to the adsorption of $\mathrm{CH}_{3} \mathrm{COO}-$ anions on the boehmite surface, which, interacting with surface $\mathrm{Al}-\mathrm{OH}$ groups [16,17], interfere with the formation of boehmite growth centers in the direction of one of the planes and incorporate crystal-forming complexes into the surface layer of phase nucleus. Sodium cations released into the aqueous suspension of $\chi-\mathrm{Al}_{2} \mathrm{O}_{3}$ do not interfere with the growth of two-dimensional and three-dimensional crystals of boehmite. As a result, the boehmite crystals predominantly form parallelepipeds and rhombs with an edge length of $\geq 200 \mathrm{~nm}$ in the alkaline medium, and the shape of rhombic plates with an edge length of $\sim 80-500 \mathrm{~nm}$ and a thickness of $\sim 20-100 \mathrm{~nm}$ in acidic medium (Figure $2 \mathrm{~b}, \mathrm{c}$ ).

The sizes of these particles exceed the CSR size of the boehmite, which depends on the duration of the HTT, its amount and $\mathrm{pH}$ of the suspension [12]. In alkaline environments, the boehmite dimensions increase with the increasing of the HTT duration and its content. They are almost unchanged in an acidic environment. Therefore, varying the $\mathrm{pH}$ of the suspension makes it possible to regulate the shape and dimensions of the boehmite crystals.

Phase transformations lead to changes in the porous system of the samples (see Table S2 in the Supplementary Materials). Both the initial $\chi-\mathrm{Al}_{2} \mathrm{O}_{3}$ and the products of its HTT are mesoporous compounds. $X-\mathrm{Al}_{2} \mathrm{O}_{3}$ is a fine-porous oxide with a high specific surface area. The sizes of mesopores are comparable with CSR values and they are probably formed by packing of oxide particles of similar sizes.

As already shown in our previous work [12], changes in the porous system of products of the HTT are due to the crystallization of boehmite and the morphology of its particles. The transformation of $\chi-\mathrm{Al}_{2} \mathrm{O}_{3}$ and the crystallization of boehmite are accompanied by a decrease in $S_{\mathrm{BET}}$ to $5-15 \mathrm{~m}^{2} / \mathrm{g}$ at $\mathrm{pH}=8.0-9.2$ and up to $155 \mathrm{~m}^{2} / \mathrm{g}$ at $\mathrm{pH}=4.0$. The process takes place equally in both alkaline and acidic media. It is to a greater extent determined by a reduction in the number or complete 
disappearance of mesopores $<3 \mathrm{~nm}$ in diameter. The volume in this region of pore diameters $\left(V_{<3 \mathrm{~nm}}\right)$ is reduced to zero. The simultaneous decrease of volume in the mesopore region with a diameter of more than $5 \mathrm{~nm}\left(V_{>5} \mathrm{~nm}\right)$ leads to a certain reduction in the value of $V_{\text {BET }}$ in samples obtained in both alkaline and acid media, but only at a boehmite concentration of not more than $40 \mathrm{wt} \%$, which is associated with a parallel increase of the medium mesopores volume with a diameter of 3-5 nm $\left(V_{3-5} \mathrm{~nm}\right)$. This is accompanied by a shift in the maximum at $D=3.4 \mathrm{~nm}$ to the region of large diameters or the appearance of an additional maximum on differential curves for the distribution of pore volumes. At these concentrations that boehmite is formed with the smallest CSR dimensions, the corresponding arrangement of which provides pores with a diameter of $4.5-5 \mathrm{~nm}$. Since the dimensions of the ones are many times smaller, we can speak of a close packing of two-dimensional and three-dimensional crystals. With a further increase in boehmite concentration $>40 \mathrm{wt} \%$ the identical pattern of changes in pore volume for alkaline $(\mathrm{pH}=8.0-9.2)$ and acid $(\mathrm{pH}=4.0)$ products of HTT is no longer noted. In the first case, the value of $V_{\mathrm{BET}}$ is reduced due to a decrease in $V_{3-5 \mathrm{~nm}}$ and $V_{>5} \mathrm{~nm}$, which is due to the dense packing of the three-dimensional particles of boehmite. When the boehmite content reaches 90-97 wt \%, the average mesopores disappear, partially broaden to $D=5.9-13.3 \mathrm{~nm}$, and their volume decreases. Large mesopores are formed only in a small amount. In the second case, the reverse process is noted at the arrangement of two-dimensional platelike particles. Increasing of the boehmite concentration from $40 \mathrm{wt} \%$ to $60 \mathrm{wt} \%$ is accompanied by an increase in the total pore volume from 0.33 to $0.42 \mathrm{~cm}^{3} / \mathrm{g}$ due to a volume increase of medium and large mesopores. The predominant formation of medium mesopores is due to the less dense packing of small dimensions plates of boehmite than parallelepipeds and rhombuses.

However, the closed mesopores were found in the samples studied in [12]. Closed mesopores with encapsulated water in the samples obtained at $\mathrm{pH}=6.0-9.2$ in addition to the open ones are formed, which are identified on the DSC curves by a characteristic endothermic effect with a temperature peak at $382-402{ }^{\circ} \mathrm{C}$. According to the TG and MS analysis, the mass loss in the region of this effect is $0.7-1.5 \mathrm{wt} \%$ of the total amount of water released when samples are heated to $1000{ }^{\circ} \mathrm{C}$. According XRD and TG/DSC/MS analysis, the closed mesopores disappear after additional heating up to $400^{\circ} \mathrm{C}$ $\left(10{ }^{\circ} \mathrm{C} / \mathrm{min}\right)$ without the boehmite $\rightarrow \chi \mathrm{Al}_{2} \mathrm{O}_{3}$ phase transformation, in which there is no gibbsite phase (Figure $6 a, b)$ ). As a result, the specific surface area increases from 7 to $8 \mathrm{~m}^{2} / \mathrm{g}$ and 5 to $6 \mathrm{~m}^{2} / \mathrm{g}$ respectively without changes in pore volume. The increase in the specific surface is due to an increase in the number of thin mesopores with a diameter less than $2.5 \mathrm{~nm}$. The intensities of the corresponding maxima on the differential curves increase almost 2-fold.

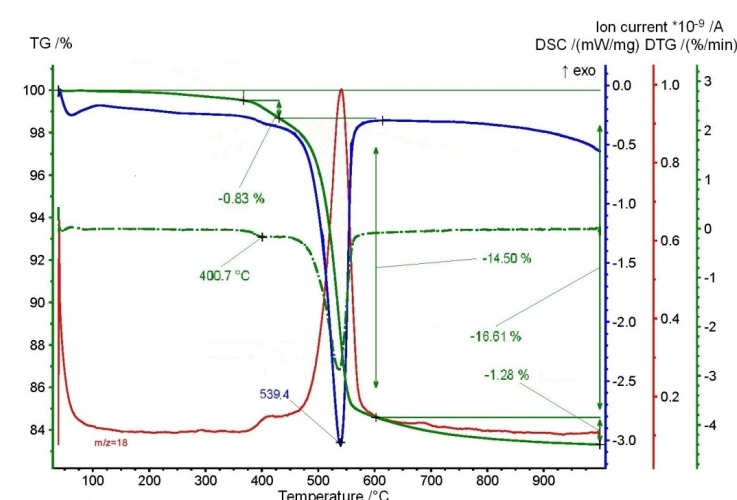

(a)

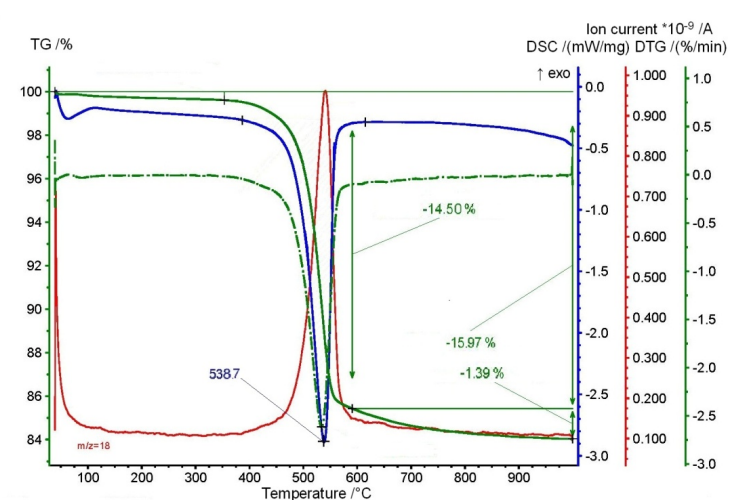

(b)

Figure 6. The thermal curves of products of HTT of $\chi-\mathrm{Al}_{2} \mathrm{O}_{3}$, obtained at (a) $\mathrm{T}=200^{\circ} \mathrm{C}, \tau=180 \mathrm{~min}$, $\mathrm{pH}=9.2$ and (b) the sample after heating up to $400{ }^{\circ} \mathrm{C}\left(10^{\circ} \mathrm{C} / \mathrm{min}\right)$.

Closed mesopores are formed by splicing large crystals of boehmite only with the shape of parallelepipeds and rhombi when their concentration in the samples reaches $\sim 25 \mathrm{wt} \%$. Closed 
mesopores are not formed in the HTT products obtained at $\mathrm{pH}=4.0$ since boehmite crystallizes only of plate form with a much smaller (1.6 times) CSR size. Based on the obtained data, we can suggest the following scheme for the formation of the porous system of products of the $x-\mathrm{Al}_{2} \mathrm{O}_{3} \mathrm{HTT}$ in alkaline and acid media (Figure 7).
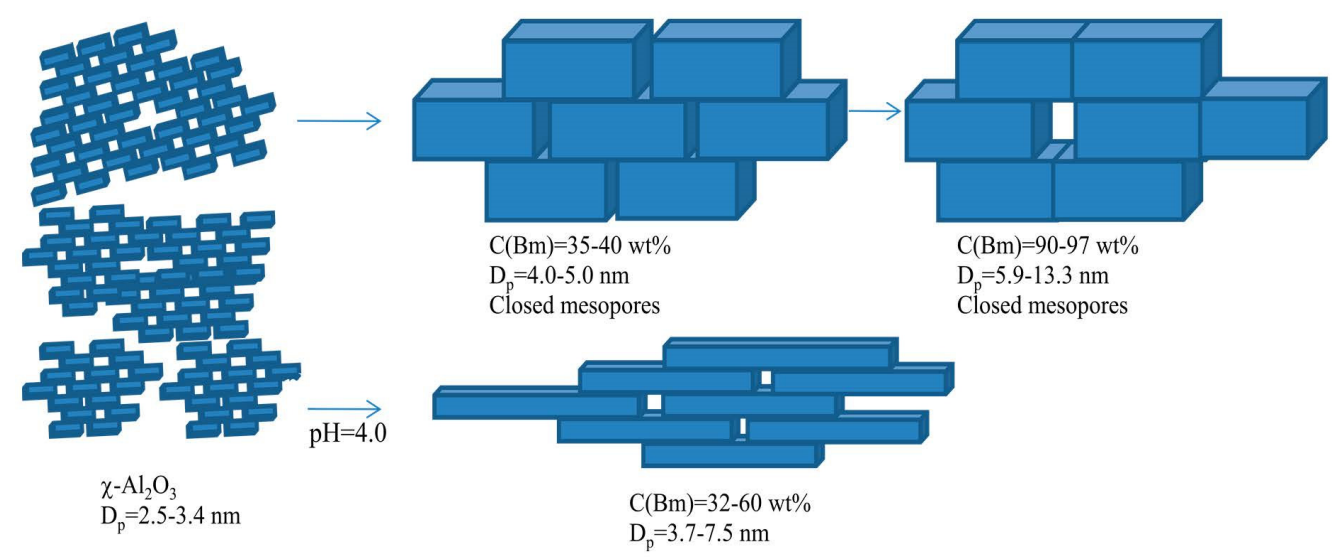

Figure 7. Formation of mesopores in the $\chi-\mathrm{Al}_{2} \mathrm{O}_{3} \mathrm{HTT}$ products.

\section{Conclusions}

The products of $x-\mathrm{Al}_{2} \mathrm{O}_{3}$ hydrothermal treatment in the aqueous suspension at $T=150-200{ }^{\circ} \mathrm{C}$ and $\mathrm{pH}=4.0-9.2$ are gibbsite and boehmite, which are formed by parallel routes. Favorable conditions for the formation of gibbsite are $T \sim 150-160{ }^{\circ} \mathrm{C}$ and $\mathrm{pH}=4.0$, when its concentration reaches $6.0-14.1 \mathrm{wt} \%$. The gibbsite undergoes a phase transformation into boehmite at $180-200{ }^{\circ} \mathrm{C}$ and $\mathrm{pH}=6.0-9.2$.

Concentration, shape and CSR size of boehmite are determined by the $\mathrm{pH}$ value of the suspension and the duration of the HTT. Three-dimensional particles are formed in the form of parallelepipeds and rhombuses at $\mathrm{pH}=8.0-9.2$, which facilitates the formation of open mesopores with a diameter of $4.0-13.3 \mathrm{~nm}$ and closed mesopores with a diameter less than $2.5 \mathrm{~nm}$ with a decrease in $S_{\mathrm{BET}}$ from 253 to $5-15 \mathrm{~m}^{2} / \mathrm{g}$ and $V_{\text {BET }}$ with 0.42 to $0.03-0.05 \mathrm{~cm}^{3} / \mathrm{g}$. Two-dimensional particles in the form of plates and mesopores with a diameter of 3.7-7.5 nm are formed at $\mathrm{pH}=4.0$, which leads to a decrease in the $S_{\text {BET }}$ value to $155 \mathrm{~m}^{2} / \mathrm{g}$ and $V_{\mathrm{BET}}$ to $0.33 \mathrm{~cm}^{3} / \mathrm{g}$. The phase transformation of $\chi-\mathrm{Al}_{2} \mathrm{O}_{3}$ into boehmite to a concentration of $90-97 \mathrm{wt} \%$ is carried out at $180-200{ }^{\circ} \mathrm{C}$ through $180 \mathrm{~min}$ of the HTT.

Supplementary Materials: The following are available online at http:/ /www.mdpi.com/2079-6412/8/1/30/s1, Table S1: TG/DSC/MS analyses results of starting $\chi-\mathrm{Al}_{2} \mathrm{O}_{3}$ and the products of its hydrothermal treatment; Table S2: Mesoporous system parameters of $\chi-\mathrm{Al}_{2} \mathrm{O}_{3}$ and the products of its hydrothermal treatment.

Acknowledgments: The work was performed according to the Russian Government Program of Competitive Growth of Kazan Federal University. The thermal analysis of samples was carried out at the Federal Center for Collective Use of the Kazan Federal University with the support of the Russian Agency for Science and Innovation by A.V. Gerasimov. The scanning electron microscopy and transmission electron microscopy measurements were performed at the Interdisciplinary Center "Analytical Microscopy" of the Kazan Federal University by V.V. Vorobiev and V.G. Evtyugin respectively.

Author Contributions: Svetlana R. Egorova, Aliya N. Mukhamed'yarova and Alexander A. Lamberov engineered and designed the experiments; Aliya N. Mukhamed'yarova, Oksana V. Nesterova, Juliya D. Skibina and Yuqing Zhang carried them out. All authors participated in the analysis of the data and writing of the paper.

Conflicts of Interest: The authors declare no conflict of interest.

\section{References}

1. Levin, I.; Kaplan, W.D.; Brandon, D.G.; Layyous, A.A. Effect of SiC submicrometer particle size and content on fracture toughness of alumina-sic "nanocomposites". J. Am. Ceram. Soc. 1995, 78, 254-256. [CrossRef] 
2. Garbarino, G.; Travi, I.; Pani, M.; Carnasciali, M.M.; Busca, G. Pure vs. ultra-pure $\gamma$-alumina: A spectroscopic study and catalysis of ethanol conversion. Catal. Commun. 2015, 70, 77-81. [CrossRef]

3. Kaya, C.; He, J.Y.; Gu, X.; Butler, E.G. Nanostructured ceramic powders by hydrothermal synthesis and their applications. Microporous Mesoporous Mater. 2002, 54, 37-49. [CrossRef]

4. Chary, K.V.R.; Ramana Rao, P.V.; Venkat Rao, V. Catalytic functionalities of nickel supported on different polymorphs of alumina. Catal. Commun. 2008, 9, 886-893. [CrossRef]

5. El-Nadjar, W.; Bonne, M.; Trela, E.; Rouleau, L.; Mino, A.; Hocine, S.; Payen, E.; Lancelot, C.; Lamonier, C.; Blanchard, P.; et al. Infrared investigation on surface properties of alumina obtained using recent templating routes. Microporous Mesoporous Mater. 2012, 158, 88-98. [CrossRef]

6. Ninduangdee, P.; Kuprianov, V.I.; Cha, E.Y.; Kaewrath, R.; Youngyuen, P.; Atthawethworawuth, W. Thermogravimetric studies of oil palm empty fruit bunch and palm kernel shell: TG/DTG analysis and modeling. Energy Procedia 2015, 79, 453-458. [CrossRef]

7. Hicks, R.W.; Pinnavaia, T.J. Nanoparticle assembly of mesoporous AlOOH (boehmite). Chem. Mater. 2003, 15, 78-82. [CrossRef]

8. Egorova, S.; Kataev, A.; Bekmukhamedov, G.; Lamberov, A.; Gil'mullin, R.; Nesterov, O. Development of technology for the production of microspherical aluminum oxide supporter for the paraffin dehydrogenation catalyst. Catal. Ind. 2009, 1, 381-390. [CrossRef]

9. Phung, T.K.; Proietti Hernández, L.; Lagazzo, A.; Busca, G. Dehydration of ethanol over zeolites, silica alumina and alumina: Lewis acidity, Brønsted acidity and confinement effects. Appl. Catal. A Gen. 2015, 493, 77-89. [CrossRef]

10. Gil'manov, K.; Nesterov, O.N.; Lamberov, A.A.; Bekmukhamedov, G.E.; Kataev, A.N.; Egorova, S.R.; Gil'mullin, R.R. Engineering problems in the operation of microspherical chromium oxide/alumina catalysts for the dehydrogenation of paraffins. Catal. Ind. 2010, 2, 270-277. [CrossRef]

11. Lippens, B.C.; de Boer, J.H. Studies on pore systems in catalysts: V. The $t$ method. J. Catal. 1965, 4, 319-323. [CrossRef]

12. Egorova, S.R.; Bekmukhamedov, G.E.; Mukhamed'yarova, A.N.; Lamberov, A.A. On the nature of phase conversions and transformations in porous system in hydrothermal processing of $\chi-\mathrm{Al}_{2} \mathrm{O}_{3}$ into boehmite. Russ. J. Appl. Chem. 2016, 89, 703-713. [CrossRef]

13. Santos, P.S.; Santos, H.S.; Toledo, S.P. Standard transition aluminas. Electron microscopy studies. Mater. Res. 2000, 3, 104-114. [CrossRef]

14. Egorova, S.; Lamberov, A. Features of phase formation and phase distribution in the dehydration of coarse gibbsite floccules. Russ. J. Gen. Chem. 2014, 84, 2364-2374. [CrossRef]

15. Novak, C.; Pokol, G.; Izvekov, V.; Gal, T. Studies on the reactions of aluminium oxides and hydroxides. J. Therm. Anal. 1990, 36, 1895-1909. [CrossRef]

16. Ma, W.; Brown, P. Mechanisms of reaction of hydratable aluminas. J. Am. Ceram. Soc. 1999, 82, $453-456$. [CrossRef]

17. Wang, Z.; Gong, J.; Ma, J.; Xu, J. In situ growth of hierarchical boehmite on 2024 aluminum alloy surface as superhydrophobic materials. RSC Adv. 2014, 4, 14708-14714. [CrossRef]

(C) 2018 by the authors. Licensee MDPI, Basel, Switzerland. This article is an open access article distributed under the terms and conditions of the Creative Commons Attribution (CC BY) license (http://creativecommons.org/licenses/by/4.0/). 